\title{
Histórias do Brasil em quadrinhos: narrativas da participação do país na Segunda Guerra Mundial*
}

Francisco César Alves Ferraz ${ }^{* *}$ João Paulo Delgado Wolff ${ }^{* *}$

\section{RESUMO}

0 objetivo deste artigo é analisar as narrativas que as histórias em quadrinhos brasileiras estabeleceram para a participação do país na Segunda Guerra Mundial. Entre as décadas de 1950 e 1970, foram editadas revistas em quadrinhos sobre este tema, e estas tiveram maiores tiragens e leitores que a produção editorial sobre 0 assunto, representando uma das poucas oportunidades de contato que o público jovem tinha, fora do ambiente escolar, sobre a época da guerra e sobre a participação brasileira neste conflito.

Palavras-chave: Histórias em Quadrinhos, Segunda Guerra Mundial, Força Expedicionária Brasileira.

0 objetivo deste artigo é analisar as narrativas que as histórias em quadrinhos brasileiras estabeleceram para a participação do país na Segunda Guerra Mundial. Entre as décadas de 1950 e 1970, foram editadas revistas em quadrinhos sobre este tema, e estas tiveram maiores tiragens e leitores que a produção editorial sobre o assunto, representando uma das poucas oportunidades de contato que o público jovem tinha, fora do ambiente escolar, sobre a época da guerra e sobre a participação brasileira neste conflito.

As histórias em quadrinhos, que, num passado não muito distante, foram consideradas uma subliteratura prejudicial ao desenvolvimento intelectual dos jovens, têm recentemente despertado interesse nos meios

\footnotetext{
* Versão ampliada e revisada de trabalho apresentado em maio de 2007, no I Encontro Nacional de Estudos da Imagem, Universidade Estadual de Londrina -PR.

*** Professor do Departamento de História Universidade Estadual de Londrina (UEL).

${ }^{* * *}$ Graduado em Ciências Sociais - Universidade Estadual de Londrina; Estagiário do Laboratório de Ensino de História/UEL.
} 
intelectuais e passaram a ser objeto de pesquisa de professores, estudiosos e artistas, representando uma importante forma de manifestação artística, política e cultural.(CIRNE, 1977; CIRNE, 1982; EISNER, 1999; GASCA \& GUBERN, 1991; ASSUMPÇÂO JR., 2001).

Segundo Moacy Cirne "é na própria raiz do consumo que se localiza a maior importância dos quadrinhos". Diferentemente de quadros, esculturas ou outras formas de arte, os quadrinhos possuem a vantagem de alcançarem a todos, podendo ser facilmente reproduzidos e comercializados. (CIRNE, 1977, p. 16).

As histórias em quadrinhos são hoje um dos mais imprescindíveis e difundidos componentes das chamadas comunicações de massa e superam o estado industrial e anônimo para se firmarem como uma forma de arte.

Como um dos meios de expressão veiculados pela indústria cultural, os quadrinhos também podem possuir funções de transmissão de valores e informações, com a vantagem de seu fácil e rápido consumo. Desde sua popularização o debate sobre seu valor na educação de jovens e crianças dividiu esoecialistas em educação, psicologia cognitiva, cultura e artes. No Brasil, este debate também ocorreu, nas décadas de 1950 e 1960, atingindo a proporção de uma "guerra santa", opondo aqueles que consideravam os quadrinhos nocivos à formação dos jovens, e do outro lado aqueles que consideravam os quadrinhos instrumentos úteis à educação. Mesmo sofrendo pressões, censuras, campanhas difamatórias, as edições em quadrinhos continuaram sendo publicadas, aumentando sempre a oferta de títulos e tiragem das revistas. (GONÇALO JR., 2004).

Tendo em vista a importância da Arte Seqüencial, universalmente empregada nas histórias em quadrinhos, representando uma "forma artística e literária que lida com a disposição de figuras ou imagens e palavras para narrar uma história ou dramatizar uma idéia". (EISNER, 1999, p.5), procuramos iniciar este trabalho com uma breve análise da técnica artística e os parâmetros estruturais adotados pelos produtores das histórias em quadrinhos brasileiras referentes a II Guerra Mundial. As histórias em quadrinhos possuem peculiaridades que moldam suas narrativas, potencializando ou limitando sua força expressiva. Dessa forma analisaremos os principais elementos formais que compõem uma história em quadrinhos: o balão, o ruído onomatopaico e o ritmo visual, que constituem os elementos fundamentais de uma possível 
estética dos comics - expressão em inglês que se tornou universal para definir as histórias em quadrinhos(CIRNE, 1977; GUBERN, 1991; LUYTEN, 1985; MOYA, 1970).

O balão, uma das principais características criativas dos quadrinhos possui formato ligeiramente circular ou retangular, tendo por finalidade expressar em seu interior diálogos, idéias, pensamentos ou ruídos. Assim como a onomatopéia, o balão representa uma instigante visualização espacial do som(CIRNE, 1977, p.26; EISNER, 1999, p.10-12).

Nos quadrinhos sobre a participação brasileira na II Guerra Mundial predomina-se o uso do balão de uma maneira sóbria. Podem ser destacadas quatro principais espécies de balões nos quadrinhos em estudo: a primeira espécie de balão possui como característica ser retangular e estarem enquadrados na parte superior do requadro (nome utilizado para se referir à moldura que contorna os objetos e as ações presentes no quadrinho); sua principal função consiste em narrar os fatos históricos dos soldados em combate, suas ações e características heróicas visando proporcionar emoção e situar historicamente o leitor na história. Muito desses balões estavam entre aspas, pois seus conteúdos eram tirados de fontes históricas. As outras três espécies de balões eram o de fala, o mais tradicional, cujo conteúdo é a conversa entre os personagens; o balão de pensamento, em que está presente o que se passa pela cabeça do pracinha e, por fim, o balão onomatopaico que contorna os ruídos expressos nos quadrinhos(EISNER, 1999, p.44-45).

Segundo Moacy Cirne, "uma boa onomatopéia (...) está para os quadrinhos assim como um ruído (bem utilizado) estápara o cinema". Responsável pordar uma "verdadeira dimensão estético-informacional" aos quadrinhos, as onomatopéias como "AAAH!", "BOOM", "POOW", "RATATA-TA....", "BRATATA-TA...", "KLANK...KLANK..KLNAK...", "CHHRUUUM", "WHOOSH", expressando sons de gritos, explosões, metralhadoras, tanques de guerra, lanç̧amento de canhões, representam uma constante em qualquer histórias de quadrinhos sobre guerra, no qual seus ruídos relacionados de modo conflitante coma a imagem proporcionam uma alta temperatura compositiva, principalmente nos quadrinho em estudo (CIRNE, 1977, p.33-34).

A força de uma história em quadrinhos não acontece pela magia formal de um plano isolado que não esteja inserido no seu contexto, não se limita a um quadro bem desenhado, cujo plano seja capaz de revelar um perfeito 
enquadramento. "É necessário que haja uma dinâmica estrutural entre todos os quadros, criando movimento e ação formais". Portanto, para que os quadrinhos atinja sua estesia é indispensável uma "relação crítica" entre o "plano bem desenhado \& enquadrado"(CIRNE, 1977, p. 35; EISNER, 1999, p.46-50; GASCA \& GUBERN, 1991, p.17-31; p. 588-605).

As histórias em quadrinhos sobre a II Guerra Mundial enfrentavam 0 desafio de quadrinizar fatos reais, nas quais a correlação entre a criação de movimentos e as ações formais representam muito bem o ritmo visual, a seqüência coerente da história. É possível, ao primeiro olhar, obter uma visão global da página, verificando-se a "funcionalidade de seus cortes e as direções de leitura", elementos que, segundo Cirne, são indispensáveis para um coerente ritmo visual do comic(FIGURA 1).

Em uma análise do ponto de vista formal concluímos que as histórias em quadrinhos de guerra possuem os elementos essenciais presentes em quadrinhos tradicionais, ou seja, a narração em sequiências de imagens, a continuidade dos personagens de uma sequiência a outra e o diálogo incluso, através dos balões, nas imagens, além do recurso da onomatopéia.

\section{Quadrinhos de guerra e as memórias da participação brasileira no conflito}

No Brasil, entre as décadas de 1950 e 1970, os quadrinhos, genuinamente nacionais, sobre a participação brasileira na II Guerra Mundial, circularam nas bancas em todo país com tiragens médias de 30 a 40 mil exemplares. Em meio às tradicionais histórias de guerra importadas e traduzidas dos Estados Unidos, vários episódios, reais ou fictícios, envolviam os soldados da Força Expedicionária Brasileira. A tiragem e a venda de tais edições superavam largamente aquelas dos livros, e representavam, em muitos casos, um dos poucos contatos que o público jovem tinha com a história da FEB e da participação brasileira na II Guerra Mundial.

Os quadrinhos brasileiros de guerra narravam histórias da FEB e da FAB, ilustrando as atuações heróicas e os momentos difíceis enfrentados pelos expedicionários brasileiros. Sua análise pode ser dividida em duas formas: as que narravam histórias reais sobre a $\mathrm{FAB}$ e a $\mathrm{FEB}$ e as que contavam histórias fictícias sobre a participação brasileira na II Guerra Mundial. 
Para esta pesquisa foi constituída uma amostra das coleções das revistas em quadrinhos de guerra, entre as décadas de 1950 e 1970, sendo analisadas dezenove edições, com mais de 100 narrativas que tinham como tema a participação brasileira na II Guerra Mundial.

As revistas que misturavam histórias reais com narrativas fictícias sobre a participação da FAB e da FEB eram: Diário de Guerra, Pelotão Suicida e Combate, e as que enfatizavam narrar histórias reais da guerra eram a Coleção de Aventuras e a Serviço Secreto, sendo que esta última não tinha como foco principal a guerra, mas entre suas edições podiam ser encontradas histórias verídicas quadrinizadas sobre a participação brasileira.

Uma das maiores dificuldades foi estabelecer as datas de publicação, pois os dados sobre mês e ano de edição muitas vezes não eram apresentados, seja nas páginas internas, seja nas capas e contra-capas. De mesma forma, informações importantes como o autor dos roteiros das histórias ou seu ilustrador eram frequientemente omitidos. Aproximações das datas de edições eram, porém, possíveis, quando se cruzavam informações na bibliografia especializada ou se atentava para as unidades monetárias (cruzeiro, cruzeiro novo) e os preços das revistas, em comparação com outros títulos publicados na mesma época.

Muitas das revistas possuíam relatos de ex-combatentes e explicações de como funcionavam os diferentes tanques de guerra, armas e aviões utilizados na II Guerra Mundial.

Os quadrinhos eram consumidos principalmente pelo público jovem, o que pode ser constatado por meio da análise da bibliografia especializada e da publicidade presente nas revistas, que anunciava produtos de modelagem física, academias de halterofilismo, cursos por correspondência, editoras populares com catálogos de introdução a ofícios técnicos, títulos de cunho erótico e de educação sexual. Através dessas informações, foi possível traçar um esboço do perfil do consumidor destas revistas de guerra, ou seja, um público predominantemente masculino, na faixa etária que compreende a adolescência até os primeiros anos da vida adulta.

Sobre a questão socioeconômica, pode-se inferir, pelo tipo de orientação profissional desses anúncios, pelo preço das revistas, pela sua linguagem popular, que seus leitores eram das classes populares, e que seu grau máximo de instrução era predominantemente de nível secundário. 
Tendo em vista que a Coleção de Aventuras era a única revista voltada para a quadrinização da participação brasileira na II Guerra Mundial, priorizaremos neste trabalho sua análise.

Coleção de Aventuras foi a primeira revista do Brasil, a publicar, na forma eminentemente popular das histórias em quadrinhos, narrativas da participação brasileira na Segunda Guerra Mundial. Tais histórias narravam os feitos heróicos dos expedicionários e momentos dramáticos vividos e contados pelos próprios combatentes, ou baseados em noticiários da época.

0 diretor da revista Coleção de Aventuras, Ilo Iloy Lund, afirmava que o objetivo de suas histórias em quadrinhos era de "divulgar e enaltecer os feitos dos soldados brasileiros, publicando suas aventuras verídicas, devidamente comprovadas e autenticadas". As coleções procuravam

sempre mostrar aos olhos de todos a bravura, a fibra e o heroísmo de que nossos pracinhas deram mostras nos campos de batalha da Europa, durante a II Segunda Guerra Mundial. Fica assim registrado (...) o nosso propósito sincero de tornar Coleção de Aventuras a maior revista do Brasil e, ao mesmo tempo, um veículo de congraçamento de todos os nosso expedicionários sob um critério jornalístico de justiça, e patriotismo (Coleção de Aventuras, Ano I, n. 1, 1957, p. 3).

Nas suas edições, o diretor Lund pedia aos ex-expedicionários que colaborassem com a revista enviando fotos e dados referentes a FEB, desde que tais dados e fotos fossem devidamente comprovados.

Naturalmente apareciam diferenças entre as narrativas de combatentes e correspondentes de guerra e suas transposições nas histórias em quadrinhos, mas tais fallhas eram justificadas pelos editores pelas dificuldades de obtenção de matérias, pela comprovação da mesma, por problemas atinentes a quadrinização e iluminação das histórias, além de erros referentes à natureza gráfica.

Assim, a revista em quadrinhos Coleção de Aventuras pretendia ser uma obra completa sobre a história da participação brasileira na II Guerra Mundial. Em suas edições, a quadrinização das histórias da guerra era precedida com texto contando a história do combatente que seria transposta para o quadrinho, com as devidas citações. Apesar de as revistas não terem qualquer ligação com as forças armadas, quem coordenava assuntos referentes às histórias 
da participação brasileira na guerra era o Capitão Adão Viana, sob colaboração do ex-combatente Paulo Vidal, autor do livro "Heróis Esquecidos", obra que trazia relatos das ações de expedicionários tombados na guerra(VIDAL, 1960). Vários trechos deste livro foram transcritos nas edições. Muitas reportagens também tinham como fonte o jornal "Tribuna da Imprensa", que eram cedidas para a revista em quadrinhos. 0 diretor de redação era Sérgio D. T. Macedo e muitos dos desenhos foram feitos por Otto Brandes e Flavio Colin. Além dessas fontes, os roteiros quadrinizados ocasionalmente citavam como base citações oficiais de combate e relatos de diversos oficiais, praças e conhecedores da guerra, que colaboravam com artigos, informações e fotografias, bem como sugestões e comentários de leitores, que eram enviadas por correspondência. 0 próprio comandante da FEB, Marechal Mascarenhas de Moraes, enviou carta para a revista, cumprimentando sua direção, por ter encontrado "na história militar do Brasil, particularmente na Força Expedicionária Brasileira, assunto de permanente atração, não só para os jovens como para o público em geral" (Coleção de Aventuras, Ano I, n. 12, 1958, p.03).

A preocupação com a "veracidade" dos fatos era constante na revista, através de reproduções de Citações de Combates, Diário de Operações dos Batalhões, Citação oficial do Comando da FEB e Boletins Especiais do Exército, entre outros materiais históricos.

Entre as edições pesquisadas podemos observar três citações nas histórias em quadrinhos referentes a fatos históricos relacionados com a participação brasileira na II Guerra Mundial: a tomada do Monte Castelo no dia 21 de fevereiro de 1945, cujo título da história em quadrinhos é A epopéia do Monte Castelo; a batalha de Montese, intitulada A mais sangrenta batalha da FEB: Montese; e, sobre o naufrágio dos navios brasileiros, a Coleção Aventuras possui duas histórias: O naufrágio da Corveta Camaquã a 31 navios torpedeados. Tais momentos históricos quadrinizados eram precedidos por textos que narravam os acontecimentos fatídicos em forma de artigo.

Podemos perceber uma constante exaltação dos combates, como por exemplo, no texto "A epopéia de Monte Castelo", que precede os quadrinhos referentes à conquista do Monte Castelo:

Monte Castelo! Uma epopéia. Centenas de vidas sacrificadas, dor, lágrimas, 
sácrifícios, muita luta, muita coragem, muito desprendimento e abnegação. Monte Castelo! Demonstração de grande valor e coragem do soldado brasileiro. Glória aos que ficaram, glória aos que voltaram - toda essa mocidade vibrante e varonil à qual o Brasil tanto deve e tão pouco lembra, à qual a Humanidade e a Democracia tanto ficaram devendo.

Talvez que sem a atuação do $1^{\circ}$ Grupo de Caça, muitas outras centenas de vidas tivessem sido sacrificadas e a tomada do Morro Maldito não houvesse sido realizada tão rapidamente.

Por isso mesmo no coração dos pracinhas ficou uma gratidão imensa pelos rapazes da FORÇA AÉRIA, os valorosos rapazes que tão bem manejaram a "SENTA A PÚA" e num momento oportuno.

Em 21 de fevereiro de 1944, dia esplêndido, dia soberbo, dia magnífico, em que foi dominado o MONTE CASTELO que foi um dos maiores sorvedouros de vidas BRASILEIRAS na ÚlTima GUERRA(Coleção de Aventuras, s/n., 1957, p.5) (maiúsculas no original).

Em termos narrativos não havia muitas sutilezas. Seguindo a caracterização básica deste tipo de veículo de comunicação de massa(VERGUEIRO, 1998, p.1-2), podem ser encontrados, nas histórias analisadas, vários exemplos de pasteurização dos conteúdos, de desprezo às individualidades sociais, assim como o uso freqüiente de estereótipos sociais e nacionais. Alemães, por exemplo, eram comumente retratados como nazistas convictos, homens cruéis, combatendo e gritando, entre uma rajada e outrade metralhadora, Heil Hitter!. Soldados brasileiros, em contrapartida, apareciam como bondosos para com os civis, criativos e espertos nas manobras individuais, para safarem-se de balas e granadas inimigas. À rigidez do combatente alemão era oposto o "jogo de cintura" do combatente brasileiro. Às vezes, os inimigos eram retratados de maneira cômica, com os balões de pensamento evocando "saudade da cerveja e do salsichão". Já os balões que expressavam os devaneios dos brasileiros lembravam do "o luar do sertão", das praias exuberantes, das namoradas, mães e noivas, num esforço de humanização do "eu" e de depreciação do "outro".

Este tipo de história não sofria crítica dos leitores de Coleção de Aventuras: na amostragem consultada, na seção de carta dos leitores, não se registra uma única crítica a este tipo de postura narrativa. Além desta, havia outra seção chamada Club dos Leitores, nas quais eram respondidas as curiosidades destes 
em relação à FAB e à FEB, sobre detalhes referentes a armas e munições, táticas de guerra empregadas durante as batalhas pelos brasileiros, etc.

A revista também tinha o papel de se preocupar com o estado dos excombatentes no pós-guerra. Algumas histórias questionavam-se sobre 0 paradeiro dos ex-combatentes e se eles estavam amparados pelos poderes públicos. Outras, quando terminavam, informavam a trajetória do pós-guerra dos personagens principais.

As histórias presentes nos quadrinhos não eram exclusivamente para os combates das Forças Brasileiras: havia também histórias de batalhas dos norteamericanos ou outras histórias de confrontos entre os Aliados e o Eixo. Normalmente tais histórias eram importadas do Estados Unidos e adaptadas e traduzidas para o português. Muitas delas eram tidas como reais, mas a maioria era fictícia. Nestas revistas, claramente havia uma exaltação dos norteamericanos, classificando-os como heróis e invencíveis. Mas a partir do número treze, devido ao grande sucesso da revista, as histórias passaram a ser exclusivamente dedicadas aos feitos heróicos dos pracinhas, sendo inteiramente nacional, com desenhos e histórias brasileiras.

Entre os heróis de guerra separamos um, que é exemplar do tipo de abordagem realizada pelas revistas. Trata-se do sargento Max Wolff Filho, que foi citado com frequiência na Coleção de Aventuras. Ele foi dos maiores heróis de guerra brasileiros, e a cena dramática de sua morte foi relatada com detalhes em célebre reportagem do correspondente de guerra Joel Silveira(SILVEIRA, 1945). Em uma das edições, é relatado que Wolff

teve seu batismo de fogo no ataque a Montese. Desde o inicio da ação o seu ímpeto, 0 seu entusiasmo, a sua agressividade, foram por todos reconhecidos. Sua capacidade de comando à frente de patrulhas, foi um dos fatores incontestes da excelente atuação de seus comandados. Max Wolff foi morto por una rajada de metralhadora germana e ganhou, post mortem, a mais alta condecoração americana de guerra concedida a estrangeiros, a ‘Silver Star' (Coleção de Aventuras, 1957, p.22-23).

Um dado relevante é que, embora ocasionalmente sejam feitas referências aos oficiais comandantes das unidades combatentes, as narrativas quadrinizadas poucas vezes fazem referências aos oficiais-superiores. A tendência observada 
na amostragem é a de valorizar preferencialmente os praças, soldados anônimos que efetivamente arriscaram suas vidas em combate. Por vezes, oficiais comandantes aparecem nas narrativas ordenando missões difíceis de serem cumpridas, ou mesmo temerariamente arriscadas.

Há, inclusive, uma narrativa, extraída do polêmico livro Depoimento dos Oficiais da Reserva da FEB, em que a própria imagem do Comandante da FEB, Marechal Mascarenhas de Moraes, é questionada, em história conhecida como 0 episódio das facas. Tratava-se de uma substituição de batalhões na frente de combate, de uma unidade norte-americana que estava exaurida, por um batalhão brasileiro. Entretanto, o batalhão da FEB indicado para substituir os norte-americanos havia acabado de voltar de um combate renhido, com baixas que não haviam sido repostas, com desfalque de armas e munições. 0 relato do livro Depoimento dos Oficiais da Reserva da FEB narra que os oficiais subalternos (tenentes e capitães, aqueles que arriscavam a vida junto com os praças na frente de combate) tentavam argumentar a inconveniência da substituição, ao que foram silenciados asperamente por Mascarenhas de Moraes, que chamou-os de covardes, e ameaçou ir pessoalmente comandar o batalhão em substituição. Quando lhe foi argumentado que faltavam armas e munições, Mascarenhas teria respondido: "Os senhores não tem facas? Cada soldado não recebeu uma faca? A munição irá depois. De qualquer forma o batalhão subirá hoje!". Contrariados, os membros do batalhão tentaram substituir os norte-americanos, que ao notarem a precariedade do batalhão substituto, se recusaram a deixar seus postos. A conseqüência de tal confusão foi uma grande movimentação de homens, notada pelos alemães, que trataram de concentrar sua artilharia no local, com saldo de baixas perfeitamente evitáveis (ARRUDA, et alii, 1949, p.72-75).

Essa narrativa foi adaptada para os quadrinhos e estes enfatizaram a diferença entre os oficiais superiores, protegidos em seus quartéis-generais, longe dos combates encarniçados, e os tenentes, "... que são os únicos chefes que vivem integralmente a vida dos pracinhas... que é sobre eles, afinal, que repousa a sorte dos planos de batalha". Os recursos visuais dos quadrinhos ressaltam essas diferenças, mostrando os soldados com semblantes cansados, sujos, com a barba por fazer, capacetes desafivelados, enquanto os oficiais 
superiores aparecem com farda bem-passada, nós impecáveis de gravata e postura arrogante(Combate, N.38, s/data, p.01-12) ${ }^{1}$ (FIGURA 2).

Assim, percebe-se uma grande diferença de postura entre os quadrinhos de guerra brasileiros (em que os heróis são os soldados, cabos, sargentos, tenentes e capitães) das "histórias oficiais" e memórias glorificadoras publicadas àquela época (em geral sob os auspícios da Biblioteca do Exército Editora), que enfatizavam os feitos dos oficiais superiores. Pode-se explicar essa diferença, em primeiro lugar, pela própria estrutura dos quadrinhos de guerra, cujo público se interessava pelas aventuras daqueles que realmente arriscaram suas vidas, e não guerreiros de gabinete. Essa estrutura é encontrável também nos quadrinhos de guerra norte-americanos e europeus (EDWARDS, 1996). Em segundo lugar, é possível interpretar tal postura dos quadrinhos de guerra pela tendência, presente em diversos agentes de memória coletiva, de valorizar os cidadãos comuns envolvidos na guerra, um fenômeno que o historiador inglês Alex King, ao estudar a construção da memória coletiva da Primeira Guerra Mundial na Inglaterra, chamou de "canonização do homem comum, do herói anônimo" (KING, 1998). Neste caso, os quadrinhos de guerra, mesmo involuntariamente, desenvolviam uma leitura alternativa da participação brasileira na guerra, o que era notável, principalmente se atentarmos para o fato de que a censura aos produtos culturais estava em seu período mais agudo.

\section{Considerações Finais}

A análise das narrativas da participação brasileira na Segunda Guerra Mundial, contidas nas revistas em quadrinhos voltadas para a temática da guerra, mostrou o investimento de tais revistas na composição e valorização da experiência histórica dos combatentes brasileiros. Ressaltando a veracidade das histórias, procurando episódios ao mesmo tempo espetaculares e emocionantes, os quadrinhos de guerra brasileiros puderam atingir um público mais expressivo que a maior parte da bibliografia memorialística da participação brasileira no conflito. Os quadrinhos de guerra, contudo, marcam diferenças com este tipo de literatura "oficial". Ao invés de glorificar os líderes militares,

1 Embora o ano não apareça, o mês é referido (dezembro). Podemos estimar que a edição é de 1967, 1968 ou 1969), pois o preço estava expresso em Cruzeiros Novos (NCR $\$ 0,50$ ), que circularam entre fevereiro de 1967 e maio de 1970. 
que no período estudado eram protagonistas ativos na arena política do país, preferiam valorizar, em imagens e textos, os cidadãos comuns, convocados ou voluntários, que lutaram com risco de vida contra o nazi-fascismo. Foi, porém, um gênero de quadrinização efêmero, pois em meados dos anos 70 as revistas de quadrinhos especializadas na temática da guerra já haviam desaparecido das bancas brasileiras, substituídos pelas revistas de terror, espionagem, aventuras e temas eróticos. Mesmo assim, é possível afirmar que algumas gerações de jovens tiveram seu contato principal com o tema da participação brasileira na guerra, através das páginas de revistas como Coleção de Aventuras, Combate, Diário de Guerra, entre outras.

\section{Referências}

ARRUDA, Demócrito, et alii. Depoimento dos Oficiais de Reserva da FEB. São Paulo: s.ed., 1949.

ASSUMPÇÂO JR.,Francisco B. Psicologia e História em Quadrinbos. São Paulo: Casa do Psicólogo, 2001.

CIRNE, Moacy. A explosão criativa dos quadrinbos. 5ed. Rio de Janeiro: Vozes, 1977.

Achiamé, 1982.

Uma introdução política aos quadrinhos. Rio de Janeiro: Angra:

EDWARDS, B. The popularisation of war in comic strips, 1958-1988. History Workshop Journal, No 42, 1996, p. 181-189,

EISNER, Will. Quadrinhos e arte seqüencial. 3ed., São Paulo: Martins Fontes, 1999.

GASCA, Luis; GUBERN, Román. El discurso del comic. Madrid: Cátedra, 1991.

GONÇALO JR. A Guerra dos gibis: a formação do mercado editorial brasileiro e a censura aos quadrinhos, 1933-64. São Paulo: Companhia das Letras, 2004.

KING, Alex. Memorials of the Great War in Britain: the symbolism of remembrance. Oxford/New York: Oxford University Press, 1998.

LUYTEN, Sonia M. Bibe (Organizadora). Histórias em Quadrinbos - leitura crítica. $2^{\circ}$ Ed., São Paulo: Paulinas: pp. 18-83, 1985.

MOYA, Álvaro. Shazam. São Paulo: Perspectiva,1970. 
RIFAS, Leonard. Cold War Comics. International Journal of Comic Art, $\mathrm{n}^{0} 1$, vol. 2, pp. 03-44, 2000.

SILVEIRA, Joel. Histórias de Pracinba. Rio de Janeiro: Ed. Leitura, 1945.

VERGUEIRO, Valdomiro. Alguns aspectos da sociedade e da cultura brasileiras nas histórias em quadrinhos. Revista Agâque. São Paulo: Universidade de São Paulo: Escola de Comunicações e Artes, http://www.eca.usp.br/nucleos/nphqeca/nucleousp/ agaque volume1 n1 algunsaspectos.asp, vol. 1, n.1, 1998.

VIDAL, Paulo. Heróis Esquecidos. Rio de Janeiro: GRD, 1960.

\section{Histórias em Quadrinhos}

Coleção de Aventuras. Ano I, s/n, Estúdio Gráfico Garimar S.A.: Rio de Janeiro, 1957. Coleção de Aventuras. Ano I, $3^{\circ}$ Edição, Estúdio Gráfico Garimar S.A.: Rio de Janeiro, 1957. Coleção de Aventuras. Ano I, n 6, Estúdio Gráfico Garimar S.A.: Rio de Janeiro, 1957. Coleção de Aventuras. Ano I, n 7, Estúdio Gráfico Garimar S.A.: Rio de Janeiro, 1957. Coleção de Aventuras. Ano I, n ${ }^{8}$, Estúdio Gráfico Garimar S.A.: Rio de Janeiro, 1957. Coleção de Aventuras. Ano I, n 9, Estúdio Gráfico Garimar S.A.: Rio de Janeiro, 1957. Coleção de Aventuras. Ano I, nº 10, Estúdio Gráfico Garimar S.A.: Rio de Janeiro, 1957. Coleção de Aventuras. Ano I, n 11, Estúdio Gráfico Garimar S.A.: Rio de Janeiro, 1958. Coleção de Aventuras. Ano I, n 12, Estúdio Gráfico Garimar S.A.: Rio de Janeiro, 1958. Coleção de Aventuras. Ano II, nº 13, Estúdio Gráfico Garimar S.A.: Rio de Janeiro, 1958. Combate. nº 15, mês 12, Taika LTDA: São Paulo, 1973.

Combate (Almanaque). nº 6/74, mês 01, Taika LTDA: São Paulo, 1974.

Combate. n 28, Taika LTDA: São Paulo, 1973.

Combate. $n^{0}$ 29, Taika LTDA: São Paulo, 1973.

Combate. nº 38, Taika LTDA: São Paulo, [197?].

Dicírio de Guerra. Ano II, nº 5, Penteado: São Paulo.

Diário de Guerra (Almanaque). Penteado: São Paulo. 
Pelotão Suicida. nº 1, Ninja: São Paulo.

Serviço Secreto. Ano I, n 12 , Estúdio Gráfico Garimar S.A.: Rio de Janeiro, 1969.

\section{Comics of Brazil: narratives of the country's participation in the second World War}

\section{ABSTRACT}

The purpose of this work is to analyze the narratives that the Brazilian comics established for the Brazilian participation in the Second World War. Between the decades of 1950 and 1970 comic books on this theme were published and they had larger circulation and more readers than the publishing output on the subject, representing one of the few opportunities of contact that the young public had, outside the school environment, about the war time as well as about the Brazilian participation in this conflict

Key words: Comics, Second World War, The Brazilian Expeditionary Force. 


\section{Figura 01}

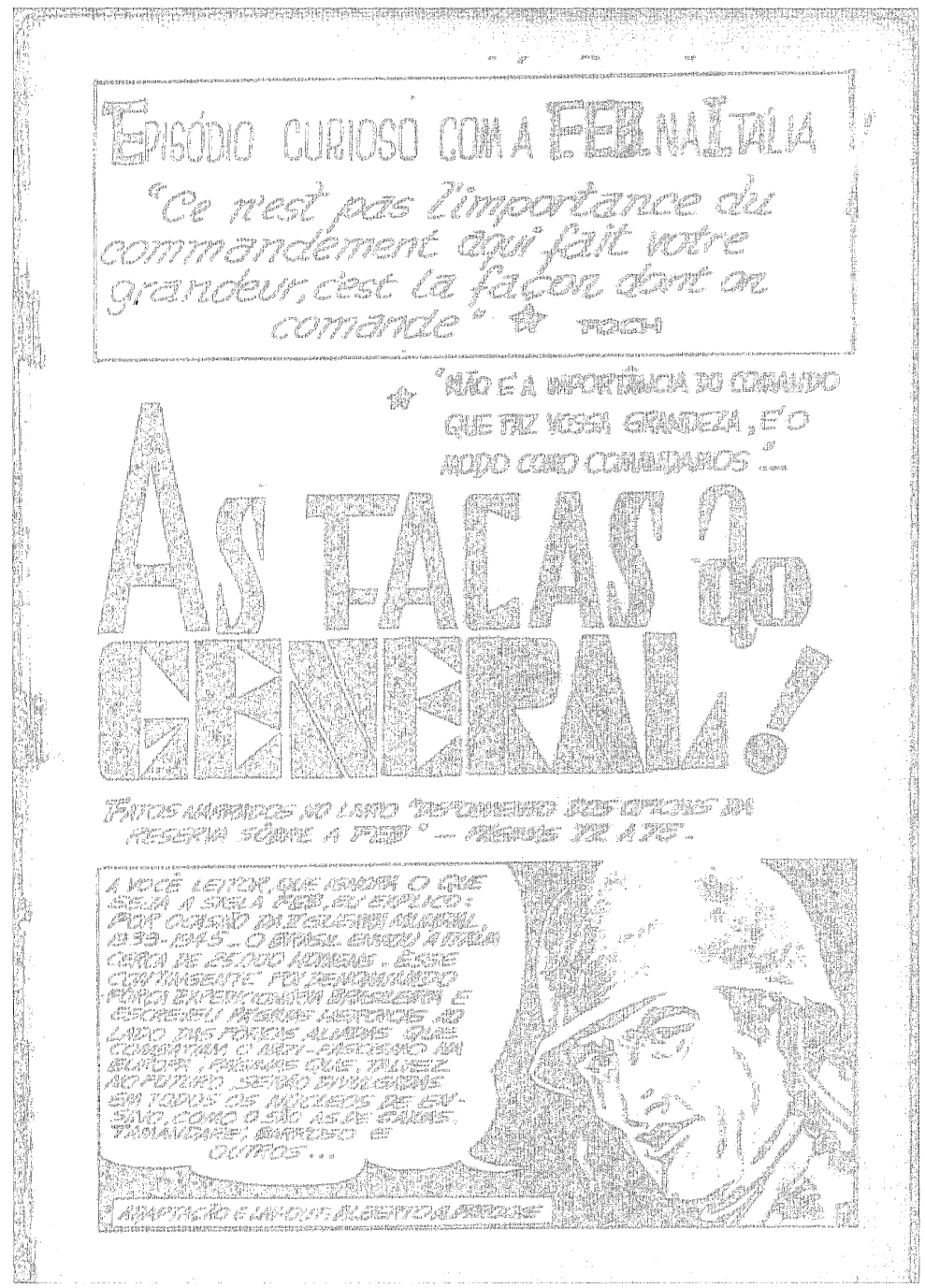



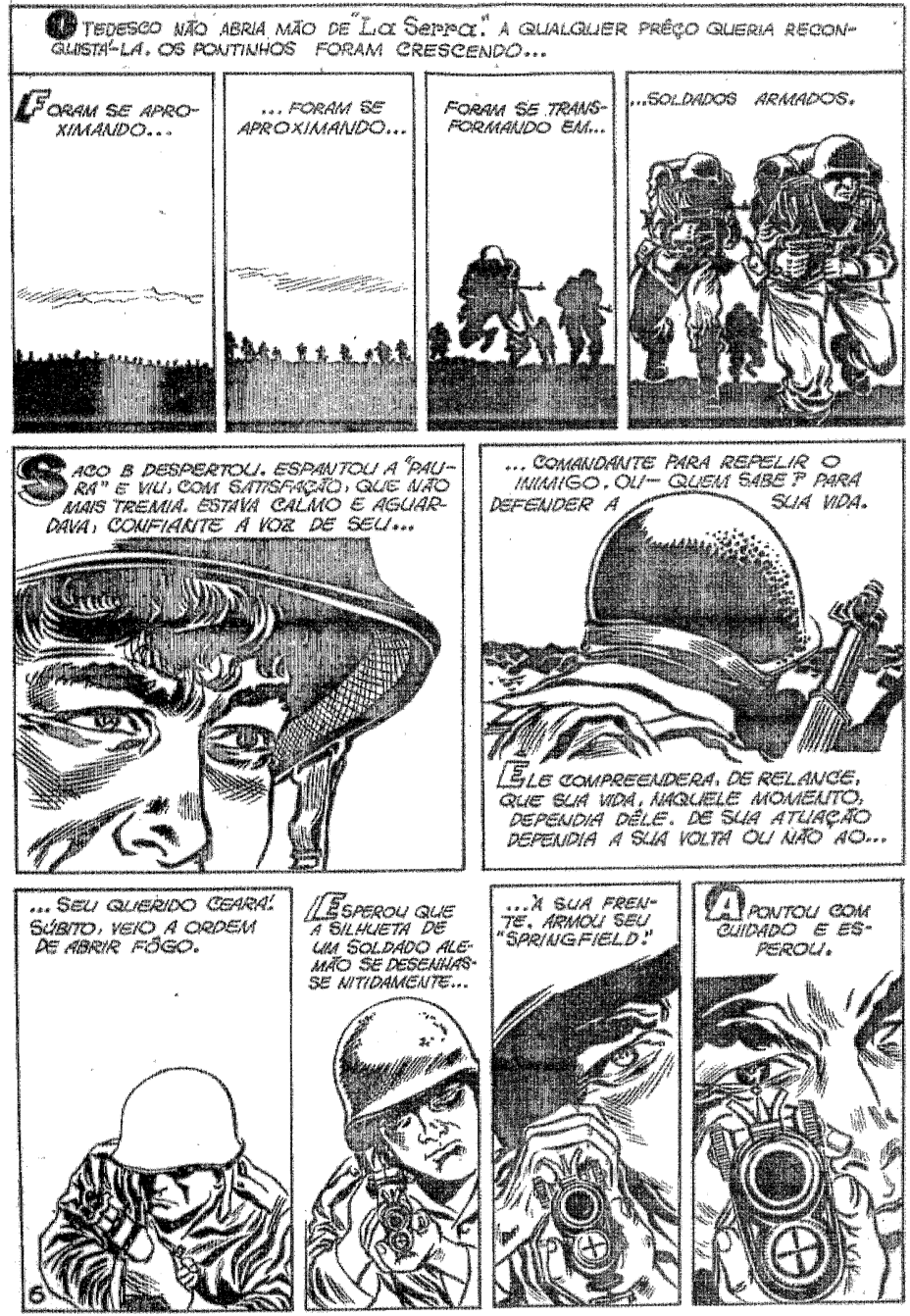

A REVISTA DO EXPEDICIONARIO 